Case Report

\title{
Malignant Catatonia Requiring High Dose Bromocriptine: Case Report
}

\author{
Edwin Meresh * , Clinton Korneffel, Bavani Rajah, Ryan Bergren \\ Loyola University Medical Center, 2160 S. First Ave, Maywood, IL 60153; E-Mails: \\ emeresh@lumc.edu; $\quad$ Clinton.E.Korneffel@luhs.org; Bavani.rajah@lumc.edu;
}

Ryan.Bergren@Va.gov

* Correspondence: Edwin Meresh; E-Mail: emeresh@lumc.edu

Academic Editor: Bart Ellenbroek

OBM Neurobiology

2021, volume 5 , issue 1

doi:10.21926/obm.neurobiol.2101089
Received: December 23, 2020

Accepted: March 15, 2021

Published: March 23, 2021

\begin{abstract}
Catatonia can occur in patients diagnosed with schizophrenia and bipolar disorder and malignant catatonia is life threatening. Anti-psychotic medications should be discontinued during acute phase of catatonia. Anti-psychotic discontinuation in catatonia is a challenge in patients maintained on long-acting injectable antipsychotics because of the extended release. Case report: We present a case of malignant catatonia developed in a patient with history of schizophrenia and developmental delay. Symptoms lasted several weeks as he was recently administered long acting injectable antipsychotic medication, requiring high dose Bromocriptine treatment. Patient required several days of bromocriptine treatment. Because of the shorter half-life, frequent and higher dosing of bromocriptine led to resolution of malignant catatonia. Malignant catatonia is a medical emergency and prompt treatment including high dose bromocriptine could lead to resolution of catatonia.
\end{abstract}

\section{Keywords}

Paliperidone palmitate; malignant catatonia; high dose Bromocriptine

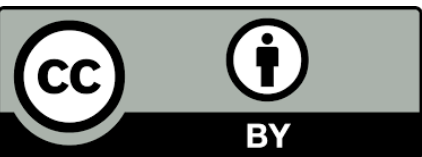

(C) 2021 by the author. This is an open access article distributed under the conditions of the Creative Commons by Attribution License, which permits unrestricted use, distribution, and reproduction in any medium or format, provided the original work is correctly cited. 


\section{Introduction}

Catatonia can occur in patients diagnosed with schizophrenia and bipolar disorder and malignant catatonia is life-threatening [1]. Anti-psychotic medications should be discontinued during acute phase of catatonia. Anti-psychotic discontinuation in catatonia is a challenge in patients maintained on long-acting injectable antipsychotics because of the extended release. Because of the extended release, malignant catatonia and neuroleptic malignant syndrome (NMS) could last several weeks [2]. We present a case of malignant catatonia developed in a patient with history of schizophrenia and developmental delay. Symptoms lasted several weeks as he was recently administered long acting injectable antipsychotic medication, requiring high dose Bromocriptine treatment.

\section{Case Report}

Patient is a 27year old male with history of schizophrenia and developmental delay and he was admitted to an outside state inpatient psychiatry facility. From there, he was emergently transferred to our multi-specialty center for work up and treatment of fever (Table 1). Patient was in the Emergency room for 3 days. Chest $x$ ray showed right basilar opacity. Vital signs: BP 136/81 | Pulse 101 | Temp $100.4^{\circ} \mathrm{F}\left(38^{\circ} \mathrm{C}\right)$ | Resp 16 | SpO2 97\%. He was started on vancomycin 1,500 mg in dextrose $5 \% 250 \mathrm{ml}$ IVPB for pneumonia. Computerized tomography (CT) showed pulmonary emboli (PE). He received enoxaparin injection. Transthoracic echocardiogram was (TTE) done with no evidence of right ventricular dysfunction.

Table 1 Initial presentation.

\begin{tabular}{llll}
\hline REASON FOR ADMIT & PSYCH HX & $\begin{array}{l}\text { PSYCHOTROPIC } \\
\text { MEDICATIONS }\end{array}$ & $\begin{array}{l}\text { WHY PSYCHIATRY } \\
\text { CONSULTED }\end{array}$ \\
\hline $\begin{array}{l}\text { Transferred from an } \\
\text { outside mental health } \\
\text { center for fever }\end{array}$ & $\begin{array}{l}\text { Schizophrenia and } \\
\text { developmental delay }\end{array}$ & $\begin{array}{l}\text { Oxcarbazepine, } \\
\text { Paliperidone palmitate } \\
\text { injection, Risperidone }\end{array}$ & $\begin{array}{l}\text { Medication } \\
\text { Adjustment }\end{array}$ \\
\hline
\end{tabular}

He was admitted to outside state inpatient psychiatry facility for 6 weeks before transfer to our facility. Per collateral history, patient was started on risperidone and valproic acid for behavioral changes, aggression and psychosis. Patient began refusing medications. 12 days before transfer to our facility, he received Paliperidone Palmitate $234 \mathrm{mg} \mathrm{IM}$ and $156 \mathrm{mg}$ IM 1 week after the first dose. Risperidone $2 \mathrm{mg}$ PO qhs and oxcarbazepine $600 \mathrm{mg}$ BID for mood symptoms were the other medications given at outside state inpatient psychiatry facility. It is not clear if oral supplementation or challenge prior to initiation of paliperidone palmitate treatment was conducted. As mentioned above, risperidone was one of his medication listed in medication list (Prior to admission list). Prior responses or adverse events with other psychiatric medications including antipsychotics was not known.

Patient was diagnosed with developmental delay at age 5. First inpatient psychiatric hospitalization was at age 18 after displaying negative symptoms (isolation, flat affect) of psychosis, and he was started on quetiapine for schizophrenia at that time. Per collateral history, patient frequently discontinued medications. He was hospitalized at outside state inpatient psychiatry facility earlier in the year and he was started on risperidone and valproic acid, patient self- 
discontinued both medications. Upon discharge, he was living with his mother, his medication intake history were unknown, he started to become more aggressive and police took him to outside state inpatient psychiatry facility for the most recent hospitalization before transfer to our facility.

His recent history of psychiatric medications (ie, duration and course of medications over the previous 3 to six months before admission to outside state inpatient psychiatry facility was unknown.

\subsection{Psychiatry Consult on Day 5}

Psychiatry was consulted on day 5 for medication adjustment (Table 2). On interview, patient spoke minimally and was often staring straight ahead. He was oriented to person, time, place and date. Given patient's acute change in mental status, moderate upper extremity rigidity, posturing, and staring episodes, there was suspicion current condition may be due to catatonia and psychosis. Lorazepam 1mg BID (twice daily) PO and aripiprazole 5mg PO nightly were given.

Table 2 Hospitalization course.

\begin{tabular}{|c|c|c|c|c|}
\hline & Day 1 to 10 & Day 11 to 14 & Day 15 to 18 & Day 19 to 23 \\
\hline $\begin{array}{l}\text { PSYCH } \\
\text { HOSP-ITAL } \\
\text { COURSE }\end{array}$ & $\begin{array}{l}\text { Vancomycin } 1,500 \text { mg in } \\
\text { dextrose } 5 \% 250 \text { ml IVPB for } \\
\text { pneumonia. } \\
\text { CT scan of chest showed } \\
\text { pulmonary embolism (PE)-BFS } \\
\text { Exam notable for: } \\
\text { Immobility and stupor, mutism, } \\
\text { Staring (fixed non-reactive), } \\
\text { Posturing, Mild to moderate } \\
\text { rigidity, resistance ( } 2 \text { out of } 3 \text { ), } \\
\text { Mild negativisms, global } \\
\text { resistance (1 out of } 3 \text { ), Notable } \\
\text { waxy flexibility (3), Some } \\
\text { withdrawal (1 out of } 3 \text { ) with the } \\
\text { BFS score of } 14 . \\
\text { Lorazepam } 1 \text { mg IV Q6H was } \\
\text { scheduled. } \\
\text { Patient had MEWS score of } 7 \text {. } \\
\text { Rapid Response Team was } \\
\text { He was transferred to Medical } \\
\text { Intensive care Unit (MICU) as his } \\
\text { temperature was } 103.1 \text { and HR } \\
137 .\end{array}$ & $\begin{array}{l}\text { BFS score of 18, } \\
\text { worsened from score } \\
\text { of 14- malignant } \\
\text { catatonia versus } \\
\text { neuroleptic malignant } \\
\text { syndrome. Increase } \\
\text { Bromocriptine } 10 \mathrm{mg} \\
\text { TID. } \\
\text { BFS improved to } 10 \\
\text { and he was transferred } \\
\text { back to general } \\
\text { medical floor. } \\
\text { Anticipating that } \\
\text { catatonia symptoms } \\
\text { will be on-going as } \\
\text { patient received } \\
\text { monthly long acting } \\
\text { injection, } \\
\text { Bromocriptine } \\
\text { increased to } 15 \text { mg } \\
\text { TID. }\end{array}$ & $\begin{array}{l}\text { On Day 17, CK } \\
\text { was up } \\
\text { trending } \\
\text { (1000->1250) } \\
\text { with increased } \\
\text { upper limb } \\
\text { rigidity, } \\
\text { Bromocriptine } \\
\text { was increased } \\
\text { to 20mg tid. } \\
\text { Rigidity and } \\
\text { tremor in } \\
\text { upper } \\
\text { extremities } \\
\text { improved, still } \\
\text { more } \\
\text { pronounced in } \\
\text { left>right. He } \\
\text { was improving } \\
\text { his PO intake } \\
\text { and } \\
\text { ambulation. }\end{array}$ & $\begin{array}{l}\text { Bromocriptine } \\
\text { was increased } \\
\text { to } 20 \text { mg four } \\
\text { times daily QID } \\
\text { Patient } \\
\text { improved he } \\
\text { stated that his } \\
\text { mood is ok, was } \\
\text { happy to be } \\
\text { walking around, } \\
\text { and hugged and } \\
\text { thanked } \\
\text { providers. } \\
\text { Patient was } \\
\text { discharged to } \\
\text { area med/psych } \\
\text { unit and was } \\
\text { discharged } \\
\text { home. }\end{array}$ \\
\hline
\end{tabular}


Bush-Francis Catatonia Rating Scale (BFS) was administered [3]. BFS exam notable for: immobility and stupor, mutism, staring (fixed non-reactive), posturing, mild to moderate rigidity, resistance (2 out of 3 ), mild negativisms, global resistance (1 out of 3), notable waxy flexibility (3), some withdrawal (1 out of 3) with the BFS score of 14.

Patient did well after lorazepam by mouth, ate his meal and went to sleep after the lorazepam. Suggesting positive response to lorazepam, lorazepam $1 \mathrm{mg}$ IV Q6H was scheduled.

\subsection{Aripiprazole 5mg PO Nightly Was Continued for 5 Days (From Day 5 to 10)}

\subsection{ICU Transfer Day 10}

On day 10, he was responsive to most questions and endorsed feeling "OK." Per medical team, patient was more interactive with improved eye contact. Lorazepam $1 \mathrm{mg}$ Intravenous (IV) was continued given progressive improvement. Later that day, patient had a Modified Early Warning Score (MEWS) [4] of 7. Rapid Response Team was called. His heart rate was in 140s, respiratory rate > 30 , Oxygen saturation $93 \%$ on room air, and temperature was 102 . Psychiatry re-evaluated patient for malignant catatonia, his BFS was 14. Bromocriptine $5 \mathrm{mg}$ PO BID was started for malignant catatonia and aripiprazole was discontinued. Lorazepam was continued.

He was transferred to Medical Intensive care Unit (MICU) as his temperature was 103.1 and HR 137. RR 40, and temperature was 103. Per MICU, diagnosis likely was Neuroleptic Malignant Syndrome (NMS) though NMS can be difficult to distinguish from malignant catatonia. MICU team agreed with Bromocriptine and Lorazepam. BFS score was 18, worsened from score of 14. Bromocriptine was titrated to $10 \mathrm{mg}$ TID. Lorazepam $1 \mathrm{mg}$ IV q6h for catatonia was continued., BFS improved to 10 and he was transferred back to general medical floor. On Day 14, BFS score was 9. VITALS BP 134/78 | Pulse 107 | Temp $100.3^{\circ} \mathrm{F}$ (37.9 $\left.{ }^{\circ} \mathrm{C}\right)$ | Resp 20 | Wt 102.6 kg (226 lb 3.2 oz) | SpO2 97\%, CK down trending (666->598)

\subsection{Bromocriptine Titration Day 17}

He showed clinical improvement in terms of speech and autonomic stability but still had mildmoderate rigidity, waxy flexibility and staring. Anticipating that catatonia symptoms will be on-going as patient received monthly long acting injection, bromocriptine was increased to $15 \mathrm{mg}$ TID. On Day 17, creatinine kinase (CK) was up trending (1000->1250) with increased upper limb rigidity, bromocriptine was increased to $20 \mathrm{mg}$ tid and titrated again to $20 \mathrm{mg}$ qid. Rigidity and tremor in upper extremities improved, still more pronounced in left>right. He was improving his PO intake and ambulation. Transfer to another hospital for Electro Convulsive Treatment (ECT) was planned as ECT is the best and proven treatment for malignant catatonia. Day 20 VITALSBP 122/81 | Pulse 105 | Temp $97.6^{\circ} \mathrm{F}\left(36.4^{\circ} \mathrm{C}\right)$ | Resp 20 | Wt $102.6 \mathrm{~kg}$ (226 lb $\left.3.2 \mathrm{oz}\right)$ | SpO2 95\% CK trending down (1251 -->971 -->885)

\subsection{Discharge Day 23}

On day 22, bromocriptine decrease was attempted, patient exhibited increased rigidity and staring episode and he was diaphoretic. Bromocriptine was increased again to $20 \mathrm{mg}$ qid. On day 23, patient was walking without assistance, he was alert and awake, with improving spontaneity of speech. Patient stated that his mood is ok, was happy to be walking around, and hugged and 
thanked providers. Bromocriptine dose was decreased to $15 \mathrm{mg}$ QID. Patient was discharged to area med/psych unit with ECT capability. That center was contacted 2 weeks after the transfer and was reported that patient was discharged home.

\section{Discussion}

Catatonia responds to benzodiazepines and ECT $[1,5]$. Reports indicate that malignant catatonia overlaps with NMS [6]. Bromocriptine is used for treating NMS [7, 8]. It is a dopamine receptor agonist on D2 dopamine receptors [9]. Anti-psychotic medications should be discontinued during acute phase of catatonia. Long-acting injectable antipsychotics could lead to prolonged period of NMS [2]. It is not clear what could have caused catatonia in our patient presented in this case report, multiple factors may have played a role. Catatonia can occur in patients diagnosed with schizophrenia and bipolar disorder. Medical conditions also cause catatonia. Malignant catatonia is life threatening, complications include PE and pneumonia [1]. Patient presented in this case report with schizophrenia and developmental delay was transferred from outside hospital due to fever, leukopenia, and suspected pneumonia. Both PE and pneumonia are complications of catatonia [1]. At the mental health center, patient was administered paliperidone palmitate injection 1 week before admission to our medical center for pneumonia and subsequent PE. Patient received Aripiprazole $5 \mathrm{mg}$ PO nightly for 5 days (from day 5 to 10). Patient presented with fever to ER and psychiatry saw patient on day 5 . Patient received diagnosis of catatonia and psychosis, lorazepam and aripiprazole were prescribed for catatonia and psychosis. Aripiprazole may have likely added to patient's worsening of catatonic symptoms. Second-generation antipsychotics are associated with NMS [10].

There are limitations to our case report. The patient was emergently transferred to our multispecialty center for work up and treatment of fever. It is not clear if oral supplementation or challenge prior to initiation of paliperidone palmitate treatment was conducted, Risperidone was one of his medication mentioned in the list. Prior responses or adverse events with other psychiatric medications including antipsychotics is not known. The main challenge while managing the patient was the extended release of antipsychotic medication from long acting anti-psychotic injection. All long acting anti-psychotic injection exhibits sustained release for days and weeks. During malignant catatonia, anti-psychotics should be avoided.

Pneumonia could lead to acute heart failure [11]. Right ventricular diastolic function in pneumonia is reported [12] and TTE will be beneficial [13]. RV dynamics were normal for patient per TTE. Patient showed clinical improvement in terms of autonomic stability, CPK and PO intake; but rigidity has been persistent. Anti-psychotic discontinuation in catatonia is a challenge in patients maintained on long-acting injectable antipsychotics because of the extended release. This could be related to the prolonged duration expected in of malignant catatonia caused by depot antipsyhcotics. Catatonia symptoms was on-going as monthly Paliperidone injection was still in his system. Bromocriptine's half-life is 3.3 hours and frequent dosing is recommended [14]. During initial treatment, Bromocriptine was administered as TID dosing and when the dose was increased to QID dosing, patient showed progress with decrease in catatonic symptoms. 


\section{Conclusion}

Malignant Catatonia is medical emergency and complications include pneumonia and PE. TTE should be considered to rule out cardiac complications of pneumonia. Anti-psychotic medications should be discontinued during acute phase of catatonia. Anti-psychotic discontinuation in catatonia is a challenge in patients maintained on long-acting injectable antipsychotics because of the extended release. ECT should be considered if available. Patients with depot induced malignant catatonia could require 2-3 weeks of bromocriptine treatment. Because of the shorter half-life, frequent and higher dosing of bromocriptine will be beneficial in malignant catatonia.

\section{Author Contributions}

All authors equally contributed to the preparation of manuscript, literature review and edition.

\section{Competing Interests}

The authors have declared that no competing interests exist.

\section{References}

1. Sienaert P, Dhossche DM, Vancampfort D, De Hert M, Gazdag G. A clinical review of the treatment of catatonia. Front Psychiatry. 2014; 5: 181.

2. Strawn JR, Keck PE Jr, Caroff SN. Neuroleptic malignant syndrome. Am J Psychiatry. 2007; 164: 870-876.

3. Bush G, Fink M, Petrides G, Dowling F, Francis A. Catatonia. I. Rating scale and standardized examination. Acta Psychiatr Scand. 1996; 93: 129-136.

4. Mathukia C, Fan W, Vadyak K, Biege C, Krishnamurthy M. Modified Early Warning System improves patient safety and clinical outcomes in an academic community hospital. J Community Hosp Intern Med Perspect. 2015; 5: 26716.

5. Trollor JN, Sachdev PS. Electroconvulsive treatment of neuroleptic malignant syndrome: A review and report of cases. Aust N Z J Psychiatry. 1999; 33: 650-659.

6. Hardy K, Evans R. Multiple episodes of NMS: Overlap with malignant catatonia. Prog Neurol Psychiatry. 2016; 20: 19-21.

7. Dhib-Jalbut $S$, Hesselbrock R, Mouradian MM, Means ED. Bromocriptine treatment of neuroleptic malignant syndrome. J Clin Psychiatry. 1987; 48: 69-73.

8. Mueller PS, Vester JW, Fermaglich J. Neuroleptic malignant syndrome: Successful treatment with bromocriptine. JAMA. 1983; 249: 386-388.

9. Bromocriptine. In LiverTox: Clinical and Research Information on Drug-Induced Liver Injury [Internet]. Bethesda, MD: National Institute of Diabetes and Digestive and Kidney Diseases; 2017.

10. Murri MB, Bugliani M, Calcagno P, Respino M, Serafini G, Innamorati $M$, et al. Secondgeneration antipsychotics and neuroleptic malignant syndrome: Systematic review and case report analysis. Drugs R D. 2015; 15: 45-62.

11. Siniorakis EE, Arapi SM, Panta SG, Pyrgakis VN, Ntanos IT, Limberi SJ. Emergency department triage of acute heart failure triggered by pneumonia; when an intensive care unit is needed? Int J Cardiol. 2016; 220: 479-482. 
12. Demirkol S, Ozturk C, Balta S, Unlu M, Arslan Z. Right ventricular diastolic function in patients with community-acquired pneumonia. Am J Emerg Med. 2015; 33: 1521-1522.

13. Yıldırım B, Biteker FS, Başaran Ö, Alataş ÖD, Acar E, Sözen H, et al. Is there a potential role for echocardiography in adult patients with CAP? Am J Emerg Med. 2015; 33: 1672-1676.

14. Crosignani PG. Current treatment issues in female hyperprolactinaemia. Eur J Obstet Gynecol Reprod Biol. 2006; 125: 152-164.

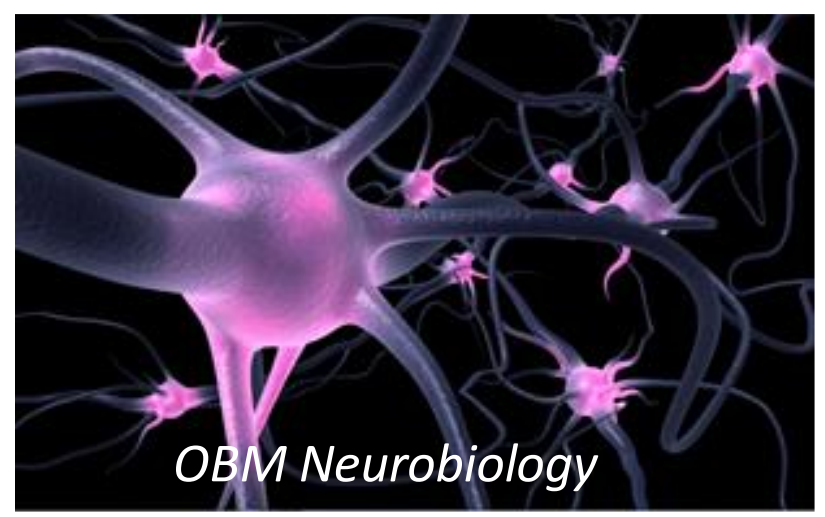

Enjoy OBM Neurobiology by:

1. Submitting a manuscript

2. Joining volunteer reviewer bank

3. Joining Editorial Board

4. Guest editing a special issue

For more details, please visit:

http://www.lidsen.com/journals/neurobiology 